\title{
Türkiye Finansal Stres Endeksi ve Markov Rejim Değişim Modeli ile Yüksek Stres Dönemlerinin Belirlenmesi ${ }^{1}$
}

Hoşeng Bülbül² Işıl Akgül ${ }^{3}$

Türkiye Finansal Stres Endeksi ve Markov Rejim Değişim Modeli ile Yüksek Stres Dönemlerinin Belirlenmesi

Öz

Gelişmekte olan ülkeler, küresel piyasalardaki gelişmelere ve sermaye hareketlerine karşı daha duyarlıdır. Bu sebeple finansal piyasalardan kaynaklı sorunlarla karşılaştıklarında oluşan finansal stresin ekonomik toparlanmayı tehlikeye atacak kadar yüksek olmaması gerekmektedir. Bu çalışmada, Türkiye için 1990:012017:02 döneminde finansal istikrarı izlemek amacıyla bir finansal stres endeksi oluşturularak politika yapıcılara fayda sağlanması amaçlanmıştır. Endekste yer verilen değişkenler, finansal piyasalardaki yüksek stres durumlarını tanımlayan değişkenler arasından seçilmiştir. Bu finansal stres endeksi için Markov rejim değişim modelleri tanımlanmış, bu modeller yardımı ile finansal piyasalardaki düşük stres, normal stres ve yüksek stres dönemleri belirlenmiştir. Yüksek stres dönemlerinin 1991, 1994, 1998, 2000-2001, 2008 kriz yıllarında yoğunlaştığı bulgusuna ulaşılmıştır. Bu da oluşturulan finansal endeksin Türkiye krizlerini öngörmede başarısını göstermektedir.

Anahtar Kelimeler: Finansal Stres Endeksi, Finansal Krizler, Markov Rejim Değişim Modeli

\begin{abstract}
Financial Stress Index of Turkey and Determination of High Stress Periods by Markov Regime Switching Model

Abstract
\end{abstract}

Developing countries are more sensitive to developments in global markets and capital movements. Therefore, their financial stress should not be high enough to put the economic recovery in danger when faced with problems originating from financial markets. In this paper, it is aimed to provide benefit to policymakers by creating a financial stress index that covers the period from 1990:01 to 2017:02 for Turkey in order to monitor financial stability. The variables included in the index are chosen among the variables that define the high stress conditions in financial markets. Markov regime switching models have been defined for this financial stress index, with the help of these models, low stress, normal stress and high stress periods in financial markets have been determined. The findings have been reached that high stress periods concentrated in the crisis years of 1991, 1994, 1998, 2000-2001 and 2008. This shows the success of the financial index to predict the crises in Turkey.

Keywords: Financial Stress Index, Financial Crisis, Markov Regime-Switching Model

\section{Giriş}

Ekonomik büyüme hedeflerine ulaşmak isteyen gelişmekte olan ülkeler, finansal serbestleşme ile birlikte gerekli sermayeyi elde etmeyi amaçlamaktadırlar. Ancak yüksek miktarlardaki sermaye giriş çıkışları özellikle 1990 'lı yıllar itibariyle bu ülkelerde finansal ve ekonomik istikrarı sağlamaktan çok finansal krizlere neden olmuştur. Bu durum Merkez Bankalarının fiyat istikrarı ve ekonomik büyüme gibi makroekonomik hedeflerinin yanında finansal istikrarı da hedeflemelerine neden olmuştur. Özellikle 2008 küresel krizinden sonra merkez bankaları açısından finan-

\footnotetext{
${ }^{1}$ Bu makale Marmara Üniversitesi Sosyal Bilimler Enstitüsü Ekonometri Anabilim Dalı'nda Prof. Dr. Işıl Akgül danışmanlığında Hoşeng Bülbül tarafından “Finansal Kriz Modelleri Çerçevesinde Türkiye'nin Kriz Öngörü Modelininin Geliştirilmesi” ismiyle tamamlanarak 01.03.2018 tarihinde savunulan yüksek lisans tezinden türetilmiştir.

2 Arş. Gör., Marmara Üniversitesi if, Ekonometri Bölümü. hoseng.bulbul@marmara.edu.tr, yazar ORCID bilgisi: http://orcid.org/ 0000-0002-4541-8916.

${ }^{3}$ Prof. Dr., Marmara Üniversitesi IF, Ekonometri Bölümü. iakgul@marmara.edu.tr, yazar ORCID bilgisi: http://orcid.org/ 0000-0003-4133-1378.
} 
sal istikrar önem kazanmıştır. TCMB da bu kapsamda 2012 yılında enflasyon hedeflemesine (fiyat istikrarı) finansal istikrar hedeflemesini eklemiş ve yeni bir politika birleşimi uygulamaya başlamıştır.

Bazı ülkelerin finansal istikrarını izlemek amacıyla, finansal sistemi yansıtan değişkenler kullanılarak çeşitli finansal stres endekslerinin geliştirildiği görülmektedir. Ancak tanımı ve ölçümü zor olan bu kavrama dair çalışmalar halen yetersizdir.

Yazında genel olarak finansal kriz modellerinde kriz tanımı olarak kullanılan finansal stres endekslerinin 0-1 değerleri alan, iki değerli değişkenler yardımı ile krizi var ya da yok olarak değerlendirdiği görülmektedir. Ancak bu endeksler stresin yoğunluğunu ölçmemekte ve kriz standartlarına yaklaşan yüksek stres durumlarını dışlamaktadır. Bu endekslerde finansal krizler sistem olayları yerine bankacılık, para veya borç krizi olarak değerlendirilmekte, böylece krizlerin eş zamanlı hassasiyetini göz ardı etmektedir. Çünkü finansal sistemde görülecek bir kriz bir başka krizin nedeni veya sonucu olarak ortaya çıkabilir, ancak bu kriz türlerini genellikle birbirinden ayırmak mümkün değildir. Bu nedenle sistemik olarak önemli olan döviz piyasası, hisse senedi ve tahvil piyasalarında finansal istikrarı bir arada analiz etmek daha uygun olacaktır. Bunun yanı sıra finansal piyasaların karşı karşıya kaldığı stres ülkeden ülkeye değişmekte olup, birçok alt bileşeni vardır. Bu bileşenler de finansal piyasalar üzerinde farklı dönemlerde farklı seviyelerde strese neden olmaktadır. Bu doğrultuda Türkiye'nin finansal istikrarını yansıtmak amacıyla Türkiye Finansal Stres Endeksi oluşturulmuştur. Serinin özellikleri dikkate alınarak oluşturulan, yani durağan ancak doğrusal olmadığı dikkate alınarak uygun modeller belirlenerek analizler yapılmıştır. Yüksek kriz dönemlerinin belirlenmesinde endeksin ve modellerin başarısı, ilgili yazına katkının yanı sıra politika koyuculara oluşturacakları modeller için de yol gösterici olacaktır.

Türkiye için 1990 Ocak-2017 Şubat yıllarını kapsayan çalışmada eşit ağırlıklandırma yöntemi kullanılarak toplulaştırılan finansal stres endeksindeki yüksek stres, normal stres ve düşük stres dönemleri Markov rejim değişim modeliyle belirlenmiştir. Endeks oluşturulurken, tüm finansal piyasayı yansıtmak amacıyla döviz piyasası, hisse senedi ve tahvil piyasası ele alınmış ve her bir piyasa için stresi yansıtan değişkenler kullanılmıştır. Endekse ilişkin Markov rejim değişim tahmin sonucunda yüksek stres dönemleri 1991, 1994, 1998, 2000-2001, 2008 yıllarında yoğunlaşmış olup, 1990 sonrası ortaya çıkan tüm krizleri yakalamıştır.

Çalışma altı bölümden oluşmaktadır. İkinci bölümde finansal stres endeksine ilişkin yazında yer alan çalışmalara değinilmiştir. Üçüncü bölümde veri setine ilişkin bilgiler verilerek finansal stres endeksinin oluşturulma aşamaları, dördüncü bölümde ise uygulamada kullanılacak yöntem anlatılmıştır. Beşinci bölümde geliştirilen TFSE endeksi için uygulama sonuçları incelenmektedir. Altıncı ve son bölümde ise elde edilen sonuçlar özetlenmektedir.

\section{Finansal Stres Endeksine ilişkin Yazın}

Yapılan yazın taramasında finansal stres endeksine ilişkin çalışmaların sınırlı sayıda olduğu görülmüştür. Bunlar arasında en bilineni, Illing ve Liu'nun (2006) Kanada için oluşturdukları makroekonomik finansal stres endeksidir. Analiz 1980-2002 dönemini kapsamaktadır. Endeks; döviz, hisse senedi, borç ve bankacılık piyasasındaki stres göstergeleri temel bileşenler yöntemiyle toplulaştırarak oluşturulmuştur. Çalışmada yüksek finansal stres düzeylerinin sadece finansal sistemi etkilemekle kalmadığı, aynı zamanda reel ekonomide de önemli kayıplara neden olduğu bulgusuna ulaşılmıştır. 
Hanschel ve Monnin (2005), İsviçre bankacılık sektörünün mevcut durumunu ekonomik dengesizlikler ile öngörmek amacıyla geliştirdikleri stres endeksini, 1987-2002 dönemi için yıllık bazda veriler kullanılarak eşit ağırlıklandırma yöntemiyle hesaplamışlardır. Elde edilen bulgulara dayanarak makroekonomik dengesizliklerin İsviçre bankacılık sektöründeki stresin önemli bir bölümünü açıkladığı sonucuna ulaşmışlardır.

Balakrishnan vd. (2009), Cardarelli, Elekdağ ve Lall (2009) tarafından gelişmiş ekonomiler için oluşturulan endekse, gelişmekte olan ekonomilerde daha sık karşılaşılan bir stres kaynağı olan döviz kuru baskı endeksini de ekleyerek gelişmekte olan ekonomiler için yeni bir finansal stres endeksi oluşturulmuştur. 1997:01-2009:03 dönemi için oluşturulan bu endekste, finansal stres dönemi, 1.5 standart sapmayı aştığı dönem olarak tanımlanmış ve krizleri doğru bir şekilde gösterdiği ifade edilmiştir.

Hakkio ve Keeton (2009), 1990-2009 döneminde Amerika Birleşik Devletleri için 11 değişken ile temel bileşenler yöntemiyle ağırlıklandırılmış ve aylık bir finansal stres endeki (Kansas City Financial Stress Index-KCFSI) oluşturmuşlardır. Finansal stresi ile ekonomik faaliyet arasındaki ilişkinin incelendiği çalışmada, yüksek stresin ekonomik faaliyeti etkilediği bulgusuna ulaşılmıştır.

Oet vd. (2011), 1991-2009 döneminde Amerika Birleşik Devletler için Cleveland Finansal Stres Endeksini (CFSI) geliştirmişlerdir. Endeks, finansal piyasaların dört sektörüne ait kredi piyasaları, döviz kuru piyasaları, hisse senedi piyasaları ve bankacılık sektörü piyasa verilerine dayanmaktadır. Endekste, finansal beta, banka bono endeksi, bankalar arası likidite endeksi, bankalar arası borçlanma maliyeti, ağırlıklandırılmış döviz kuru endeksi, faiz endeksi, hisse senedi endeksi, hisse senedi oynaklığı, likidite endeksi, hazine tahvil endeksi, hazine getiri eğrisi yayılımı olmak üzere 11 bileşen kullanılmıştır. Elde edilen bulgulara göre endeks, sistemik stresi izlemek amacıyla erken uyarı göstergesi olarak kullanılabilir.

Hollo vd. (2012), Sistemik Stresin Bileşik Göstergesi (Composite Index of Systemic StressCISS) olarak adlandırılan ve yazında öne çıkan bir endeks geliştirilmişlerdir. Analiz 1999-2011 dönemini kapsamaktadır. CISS endeksinin temel yeniliği, portföy teorisisin kullanılmasıdır. Burada endeksi oluşturan alt endeksler, zamanla değişen çapraz korelasyon yapısını yansıtan ağırlıklara dayanarak oluşturulmuştur. CISS endeksindeki kriz eşiklerinin belirlenmesi ve finansal stres dönemlerinin ayırt edilebilmesi amacıyla doğrusal olmayan zaman serisi modellerinden olan rejim geçiş modelleri kullanılmıştır. CISS'in finansal sistemik stresi ölçmede başarılı bir performans sergilediği ortaya konmuştur.

Vermeulen vd. (2015), 1980- 2010 döneminde 25 OECD ülkesi için oluşturdukları finansal stres endeksinde, değişkenler standartlaştırıldıktan sonra, ağırlıklandırılmadan toplulaştırma yaklaşımı izlemişlerdir. Finansal stresi açıklayan öncü göstergeler, Bayesci Model ortalamasıyla belirlenmiştir. Finansal stres endeksi bağımlı değişken iken, öncü göstergelerin bağımsız değişken olarak alındığı panel veri modelinde endeksin dinamiklerini açıklamanın zorluğunun yanı sıra finansal stres artışlarının öngörülmesinin de zor olduğu bulgusuna ulaşılmıştır.

Elekdağ vd. (2010), döviz piyasası baskı endeksi, ülke tahvil endeksi, hisse senedi getirileri, hisse senedi getirileri belirsizlik algısı, bankacılık sektörü riskliliğini ölçen "beta” değerini kullanarak 1997-2009 dönemi için Türkiye finansal stres endeksi geliştirmişlerdir. Endeks, Rusya Krizi, 2001 Türkiye bankacılık krizi, Irak savaşı ve 2008 krizinin yarattığı stresleri başarılı bir biçimde yansıtılmıştır. Ancak 2008 krizinde finansal stresteki artış Türkiye'de gelişmiş ve geliş- 
mekte olan ekonomilere göre daha azdır. Bunun nedenini ise Türk bankacılık sektörünün risklerinin sınırlı ve yüksek sermaye oranlarıyla sağlam bir yapıya sahip olması şeklinde yorumlanmıştır.

Çevik vd. (2013) de 1997-2010 dönemleri arasında Türkiye için finansal stres endeksi geliştirmişlerdir. Endeks, ekonomik faaliyetleri önemli bir biçimde etkileyen temel göstergelerden yararlanılarak oluşturulmuştur. Endekste hisse senedi piyasası riskliliği, bankacılık sektörü riskliliği, döviz kuru riski, ülke riski, dış borç, ticaret finansmanı, kredi riski, para piyasası endeksi, hisse senedi piyasası endeksi olmak üzere 9 farklı gösterge temel bileşenler analiziyle toplulaştırılmıştır. Endeks; Rusya Krizi, 2001 Türkiye krizi, Irak Savaşı ve 2008 küresel krizinin yarattığı stresleri yakalayarak Elekdağ vd. (2010) tarafından yapılan çalışmaya paralel sonuçlar vermiştir.

Öztürkler ve Türkmen (2013), Türkiye için daralma dönemlerini makul bir süre öncesinde öngörmeyi sağlamak amacıyla geliştirdikleri finansal stres endeksinde, yükselen piyasalar tahvil endeksi, ticaret açığının rezervlere oranı ve döviz kuru oynaklığı değişkenleri temel bileşenler analiziyle toplulaştırılmıştır.1998-2012 dönemi için oluşturulan endeks, daralma dönemini çok değişkenli dinamik probit modeliyle üç ay öncesinden öngörebilmektedir.

Ekinci (2013), 2002-2013 dönemi kapsamında Türkiye ekonomisini, oluşturduğu finansal stres endeksi çerçevesinde yüksek stres dönemi, normal stres dönemi, küresel kriz dönemi, düşük stres dönemi, yükselen stres dönemi ve azalan stres dönemi olmak üzere altı dönemi dikkate alarak incelemiştir. Endekste bankacılık sektörü için 3 aylık TRLiBOR-TCMB politika faizi, kamu sektörü için Türkiye'nin 5 yıllık dolar cinsi CDS değeri, hisse senedi piyasası için BíST100 endeksinin yıllık değişimi, döviz kuru piyasası için ise TL/ABD dolar kurunun yıllık değişimi kullanılmıştır.

Adanur Aklan vd. (2015), 2002-2014 dönemi arasında aylık veriler kullanarak oluşturdukları Türkiye finansal stres endeksinde alt endeksler faktör analizi kullanılarak ağırlıklandırımıştır. Finansal stres endeksi ve ekonomik büyüme arasındaki ilişki nedensellik analizi ile ortaya konmuştur. Elde edilen bulgulara dayanarak finansal şokların ekonomik faaliyet üzerinde olumsuz ve azalan bir etkiye sahip olduğunu ifade etmişlerdir.

Çamlıca ve Güneş (2016), finansal stres yazınında en çok kullanılan tahmin yöntemlerini 2002-2015 dönemleri arasında Türkiye ekonomisinde yaşanan finansal stres çerçevesinde karşılaştırmışlardır. Bu çalışmada, Portföy teorisi ağırlıklandırma yönteminin eşit varyans ağırlıklandırma ve temel bileşenler analizine göre finansal stres dönemlerini daha iyi yakaladığı sonucuna ulaşılmıştır.

\section{Finansal Stres Endeksinin Oluşturulması}

Risk veya belirsizlikte artan finansal stres, aslında kırılgan bir finansal yapının ve şokların sonucudur. Finansal koşullar zayıf olduğunda bir şokun aşırı stresle dolayısıyla krizle sonuçlanma olasılığı daha yüksektir. Bu nedenle finansal sistemin karşılaştığı şokun büyüklüğü ve bu şokun finansal sistem kırılganlıklarıyla olan etkileşimi, stres seviyesini belirler (Illing ve Liu, 2003: 2). Sağlam bir piyasada bile aşırı dışsal şoklar olması durumunda finansal stres yaşanabilir. Bu doğrultuda finansal stresi belirlemek ve izlemek amacıyla, finansal stresin ölçülmesi önemli hale gelmiş ve finansal stres endeksleri oluşturulmuştur.

Finansal stres endeksinin (FSE) genel amacl, finansal piyasalardaki mevcut istikrarsızlık durumunu ortaya koymak, yani sistemdeki sürtünme, gerilme ve zorlanma düzeylerini ölçmek ve bunu sürekli olan tek bir istatistiki değişkenle özetlemektir (Hollo vd., 2012: 2). 
Finansal piyasalarda strese yol açan faktörler, finansal sistemin karşılaştığı krizler çerçevesinde ele alınmıştır. Finansal stres endeksi oluşturulurken değişken seçiminde kullanılan temel kriter, endeksin birden çok finansal sistemi kapsaması olmuştur. Bu amaçla döviz piyasası, hisse senedi piyasası ve tahvil piyasası olmak üzere her bir piyasa için stresi yansıtan değişkenler kullanılmıştır.

Çalışmanın analiz dönemi 1990:01-2017:02 yıllarını kapsamaktadır. Veriler T.C.M.B Elektronik Veri Dağıtım Sistemi ve International Financial Statistics Database'den (IFS Database) elde edilmiştir. 1990 sonrası hem yurt içi hem yurt dışı kaynaklı finansal piyasalardaki bozulmalar, Türkiye ekonomisinde daralmalara neden olmuştur. Bu nedenle analiz döneminin 1990 yılından başlamasının uygun olacağı düşünülmüştür.

\subsection{Döviz Kuru Piyasası Stresi}

Döviz krizleri genel olarak, devalüasyon, rezervlerdeki kayıp ve / veya faiz oranı artışları ile tanımlanmaktadır. Döviz krizi tanımlarında, döviz kuru değişimlerinin ağırlıklı ortalaması ve rezerv kayıplarını dikkate alan yaklaşımlarda, döviz kurunu oluşturan stokastik süreç hakkında potansiyel önemli bilgiler dikkate alınmadığı için eleştirilmektedirler (Sauer ve Bohara, 2001: 135).

Döviz kuru oynaklığının artması, risk algısının önemli bir göstergesi olarak kabul edilmektedir. Ayrıca yatırımcıların yerel para biriminin temel değeri hakkındaki belirsizlik algısını ve yatırım davranışları hakkındaki belirsizliği yansıtmaktadır. Bu nedenle finansal stresin belirlenmesi aşamasında ciddi bir öneme sahiptir (Illing ve Liu, 2003: 5).

Döviz piyasasındaki stresi tanımlamak ve stokastik süreç hakkındaki potansiyel bilgileri dikkate almak için döviz kuru oynaklığının hesaplanmasında Otoregresif Koşullu Değişen Varyans (ARCH) ailesi modellerinden yararlanılmıştır. Analizler sonucunda döviz kuru getirisi için uygun ortalama denkleminin $\operatorname{ARMA}(0,2)$ ve koşullu varyans modelinin $\operatorname{GARCH}(1,1)$ olduğu belirlenmiştir. Tablo 1 'de ARMA(0,2)-GARCH(1,1) modelinin tahmin değerleri verilmiştir. DKG, döviz kurunun logaritmik farkı alınarak hesaplanan döviz kuru getirisini göstermektedir.

Tablo 1: $\operatorname{ARMA}(0,2)-G A R C H(1,1)$ Modeline ilişkin Sonuçlar

\begin{tabular}{|c|c|c|c|c|}
\hline \multicolumn{5}{|c|}{ Ortalama Denklemi: $D K G_{t}=\beta_{1}+\varepsilon_{t}+\beta_{2} \varepsilon_{t-1}+\beta_{3} \varepsilon_{t-2}$} \\
\hline & Katsayı & Standart Hata & z-İstatistiği & Olasılık Değeri \\
\hline$\beta_{1}$ & 0.0228 & 0.0024 & 9.1540 & 0.0000 \\
\hline$\beta_{2}$ & 0.6035 & 0.0590 & 10.227 & 0.0000 \\
\hline$\beta_{3}$ & 0.1882 & 0.0562 & 3.3475 & 0.0008 \\
\hline \multicolumn{5}{|c|}{ Koşullu Varyans Denklemi: $h_{t}=\alpha_{1}+\alpha_{2} \hat{\varepsilon}_{t-1}^{2}+\alpha_{3} h_{t-1}$} \\
\hline$\alpha_{1}$ & 0.0002 & 0.00005 & 2.6669 & 0.0077 \\
\hline$\alpha_{2}$ & 0.3900 & 0.1116 & 3.4921 & 0.0005 \\
\hline$\alpha_{3}$ & 0.5037 & 0.0983 & 5.1236 & 0.0000 \\
\hline T-DIST-DOF & 4.8735 & 1.3550 & 3.5966 & 0.0003 \\
\hline Varsayım & Test İst & & Prob. & \\
\hline ARCH - Test F(12,300) & 6.462 & & 0.8910 & \\
\hline
\end{tabular}

Aşağıda Tablo 2'de korelasyon matrisi yardımıyla döviz kuru (DK), döviz kuru getirisi (DKG) ve döviz kuru oynaklığı (DKO) arasındaki ilişki ortaya konmuştur. Burada amaç, hangi ekonomik büyüklüğün stres göstergesi olarak alınacağının belirlenmesidir. Döviz kuru getirisi ve döviz kuru 
oynaklığı arasındaki ilişkili yüksek olduğu görülmektedir. Bu nedenle döviz kuru stres göstergesi olarak döviz kuru oynaklığı tercih edilmiştir.

Tablo 2: Döviz Kuru Piyasası - Korelasyon Matrisi

\begin{tabular}{cccc}
\hline & DKG & DKO & DK \\
\hline \hline DKG & 1.0000 & & \\
DKO & 0.8396 & 1.0000 & \\
DK & -0.2981 & -0.1999 & 1.0000 \\
\hline
\end{tabular}

Kaminsky, Lizondo ve Reinhart'ın (1998) spekülatif baskı endeksi tanımında döviz kurundaki değişim ve rezervlerdeki düşüş yer almaktadır. Bunun nedeni, döviz krizinin sadece sabit kur rejiminde değil, esnek kur rejiminde de ortaya çıkabilecek olmasıdır. Bu nedenle spekülatif kriz, döviz kuru ve rezervlerdeki keskin düşüşlerin bir bileşimi olarak tanımlanmıştır. Bu bilgiye dayanarak bu çalışmada döviz piyasası stresini tanımlamak amacıyla uluslararası rezervler de endekse dahil edilmiştir.

\subsection{Hisse Senedi Piyasası Stresi}

Hisse senedi krizleri, genel piyasa endeksinde keskin bir düşüş olarak tanımlamaktadır. Düşüş, beklenen kayıpların artmasının, muhtemel kayıpların dağılımının yüksek olmasının veya firmaların geri dönüşleri ile ilgili belirsizliklerin arttığının göstergesi olabilir (Illing ve Liu, 2003: 6).

Yazın taramasında finansal stres endeksi oluşturma aşamasında hisse senedi endeksinin, hisse senedi getirilerinin veya hisse senedi oynaklığının analizlerde kullanılan stres göstergeleri olduğu görülmüştür. Hisse senedi oynaklığı, hisse senedi fiyatlarındaki büyük dalgalanmaların hisse senedi piyasasındaki finansal dengesizlikleri yansıttığı varsayılarak kullanılabilecek değişkenlerden biridir.

Bu aşamada hisse senedi piyasası oynaklığının hesaplanması amacı ile ARCH ailesinden çeşitli modeller denenmiş ve en uygun modelin $\operatorname{ARMA}(0,1)-\operatorname{EGARCH}(1,1)$ olduğu belirlenmiştir. Aşağıda Tablo 3' de hisse senedi getiri serisi için elde edilen ARMA $(0,1)-\operatorname{EGARCH}(1,1)$ modelinin tahmin sonuçları verilmiştir.

Tablo 3: $\operatorname{ARMA}(0,1)-\operatorname{EGARCH}(1,1)$ Modeline ilişkin Sonuçlar

\begin{tabular}{|c|c|c|c|c|}
\hline \multicolumn{5}{|c|}{ Ortalama Denklemi: $B G_{t}=\beta_{1}+\varepsilon_{t}+\beta_{2} \varepsilon_{t-1}$} \\
\hline & Katsayı & Standart Hata & z-İstatistiği & Olasılık Değeri \\
\hline$\beta_{1}$ & 0.0189 & 0.0062 & 3.0540 & 0.0023 \\
\hline$\beta_{2}$ & 0.3268 & 0.0526 & 6.2089 & 0.0000 \\
\hline \multicolumn{5}{|c|}{ Koşullu Ortalama Denklemi: $\log \left(h_{t}\right)=\alpha_{1}+\alpha_{2}\left|\frac{\varepsilon_{t-1}}{\sqrt{h_{t-1}}}\right|+\alpha_{3} \frac{\varepsilon_{t-1}}{\sqrt{h_{t-1}}}+\alpha_{4} \log \left(h_{t-1}\right)+\varepsilon_{t}$} \\
\hline$\alpha_{1}$ & -0.1556 & 0.0796 & -1.9533 & 0.0508 \\
\hline$\alpha_{2}$ & 0.1123 & 0.0527 & 2.1306 & 0.0331 \\
\hline$\alpha_{3}$ & 0.0654 & 0.0355 & 1.8409 & 0.0656 \\
\hline$\alpha_{4}$ & 0.9873 & 0.0118 & 83.306 & 0.0000 \\
\hline T-DIST-DOF & 15.0911 & 13.586 & 1.1107 & 0.2667 \\
\hline Varsayım & Test İstatistiği & & Prob. & \\
\hline ARCH - Test F(12,300) & 6.5198 & & 0.8876 & \\
\hline
\end{tabular}

Hisse senedi için hangi ölçeğin kullanılacağına karar verilmesi gerekmektedir. Bu amaçla hisse senedi oynaklığı (BO), hisse senedi getirileri (BG) ve hisse senedi endeksi (BIST100) için 
korelasyon matrisi Tablo 4'de verilmiştir. Oynaklık ve getiri serilerinin birbiriyle ilişkilerinin yüksek olması nedeniyle hisse senedi piyasası oynaklığının en iyi gösterge olacağı düşünülerek endekse katılmıştır.

Tablo 4: Hisse Senedi Piyasa Değişkenleri -Korelasyon Matrisi

\begin{tabular}{lccc}
\hline & BG & BO & BisT100 \\
\hline \hline BG & 1.0000 & & \\
BO & 0.9492 & 1.0000 & \\
BisT100 & -0.1127 & -0.0898 & 1.0000 \\
\hline
\end{tabular}

\subsection{Tahvil Piyasası Stresi}

Yatırımcıların risk algılamalarındaki değişiklikler, gelişmekte olan ülkeler için finansal stresin önemli bir göstergesi olarak kabul edilir. Tahvil piyasası stresini yansıtmak için Türkiye ve ABD arasındaki faiz oranı endeksleri, Türkiye'de risk algılamasının bir göstergesi olarak kullanılabilmektedir (Çevik vd., 2013: 375). Vermeulen vd. (2015) risk ölçüsü olarak, ülke içi politika faiz oranı ve ABD politika faiz oranı arasındaki farkı tahvil piyasası stres göstergesi olarak kullanmışlardır. Faiz oranları arasındaki fark, döviz kurundaki azalma beklentisini kapsaması için kullanımaktadır. Yani bu değişken bir beklenti değişkenidir (Martinez-Peria, 1999: 14).

Özetlenecek olursa, endekste kullanılacak olan alt piyasa stres göstergeleri; döviz piyasası stres göstergesi olarak döviz kuru oynaklığı (DKO), hisse senedi piyasa göstergesi olarak hisse senedi getiri oynaklığı (BO), tahvil piyasası stres göstergesi olarak ülke içi politika faiz oranı ve ABD politika faiz oranı arasındaki fark (FOF) olarak belirlenmiştir. Ayrıca endeks, döviz krizi tanımlarından yola çıkarak oluşturulmuştur. Döviz krizinin, döviz kurundaki değişim ve rezerv miktarındaki azalma olarak tanımlanmasından hareketle uluslararası rezervler (REZ) de döviz kuru stres göstergesi olarak endekse katılmıştır.

\subsection{Eşit Ağırlıklandırma Yöntemi}

Finansal stres endeksinin oluşturulma aşamasında her bir stres göstergesini tek bir endeks içerisinde toplulaştırmak amacıyla eşit varyans ağırlıklandırma yönteminden yararlanılmıştır. Illk olarak her bir piyasa stres göstergesini aynı birim ile ifade etmek için standartlaştırma işlemi uygulanmıştır. Stres göstergeleri, normal dağılım varsayımı altında örneklem ortalaması ve standart sapması kullanılarak Eşitlik (1)'e göre standartlaştırılmıştır;

$$
Z_{i}=\frac{x_{i-} \mu}{\sigma}
$$

Eşitlik (1)'de $Z_{i},(i=1,2,3,4)$ standartlaştırılmış değişkenleri gösterirken, $x$ her bir piyasa stresini yansıtması için kullanılan stres göstergesi, $\mu$ örneklem ortalaması ve $\sigma$ örneklem standart sapmasıdır.

Eşit varyans ağırlıklandırma yönteminde her bir alt piyasa göstergesine eşit ağırlık verilmektedir. Burada tüm finansal sistem içinde her bir piyasasının eşit öneme sahip olduğu kabul edilmektedir. Pozitif endeks değerleri, finansal stresin uzun dönemli ortalamasının üzerinde bulunduğunu göstermektedir. Eşit varyans ağırlıklandırma yönteminin seçilme nedeni, kolay uygulanabilir ve yorumlanabilir olmasıdır (Balakrishnan vd., 2009:9).

Aşağıda ise Eşitlik (1)'deki yaklaşımla standartlaştırılmış değişkenlerin ağırlıklı ortalaması alınarak toplulaştırma işleminin yapılışı görülmektedir:

$$
F S E=\frac{\sum_{i=1}^{n} Z_{i}}{n}
$$




\subsection{Türkiye Finansal Stres Endeksi}

Tüm değişkenleri aynı birimde ifade edebilmek, aynı zamanda karşılaştırma da yapabilmek için ortalaması ve standart sapması hesaplanan her bir değişken standartlaştırıldıktan sonra endekse dahil edilmiştir. Standartlaştırma sonrasında aynı birimle ifade edilen değişkenlerin toplulaştırılmasında değişkenlerin alacakları ağılıklar eşit varyans ağırlıklandırma ile belirlenmiştir.

Türkiye finansal stres endeksi (TFSE) aşağıdaki şekilde elde edilmiştir:

$$
\mathrm{TFSE}_{t}=\left(\frac{\left(\mathrm{DKO}_{t}-\mu_{\mathrm{DKO}}\right)}{\sigma_{\mathrm{DKO}}}+\frac{\left(\Delta \mathrm{LNREZ}_{t}-\mu_{\triangle \mathrm{REZ}}\right)}{\sigma_{\triangle \mathrm{REZ}}}+\frac{\left(\Delta \mathrm{LNFOF}_{t}-\mu_{\Delta \mathrm{FOF}}\right)}{\sigma_{\triangle \mathrm{FOF}}}+\frac{\left(\mathrm{BO}_{t}-\mu_{\mathrm{BO}}\right)}{\sigma_{\mathrm{BO}}}\right) / 4
$$

Burada $L N$, e-tabanına göre logaritmik dönüşümü; $\Delta$, fark işlemcisini; $\mathrm{DKO}_{t}$, döviz kuru oynaklığını; $\mathrm{REZ}_{t}$, altın hariç net uluslararası rezervleri; $\mathrm{FOF}_{t}$, ülke içi politika faiz oranı ile $\mathrm{ABD}$ politika faiz oranı arasındaki farkı ve $\mathrm{BO}_{t}$, hisse senedi oynaklığını; $\mu_{\mathrm{DKO}}$, döviz kuru oynaklığının ortalamasını; $\mu_{\Delta \mathrm{REZ}}$, rezerv değişiminin ortalamasını; $\mu_{\Delta \mathrm{FOF}}$, faiz oranı farkının değişiminin ortalamasını; $\mu_{\mathrm{BO}}$, hisse senedi oynaklığının ortalamasını; $\sigma_{\mathrm{DKO}}, \sigma_{\Delta \mathrm{REZ}}, \sigma_{\triangle \mathrm{FOF}}$ ve $\sigma_{\mathrm{BO}}$ sırasıyla döviz kuru oynaklığının, rezerv değişiminin ve faiz oranı farkının değişiminin ve hisse senedi oynaklığının standart sapmalarını göstermektedir. Grafik 1'de, hesaplanan finansal stres endeksinin (TFSE) grafiği verilmiştir. TFSE'nin 1991, 1994, 2001, 2008 krizlerini başarılı bir şekilde yakalarken 2004, 2006, 2011 ve 2013 dönemlerini de stresi yüksek dönemler olarak yakaladığı görülmektedir.

\section{Grafik 1: Türkiye Finansal Stres Endeksi}

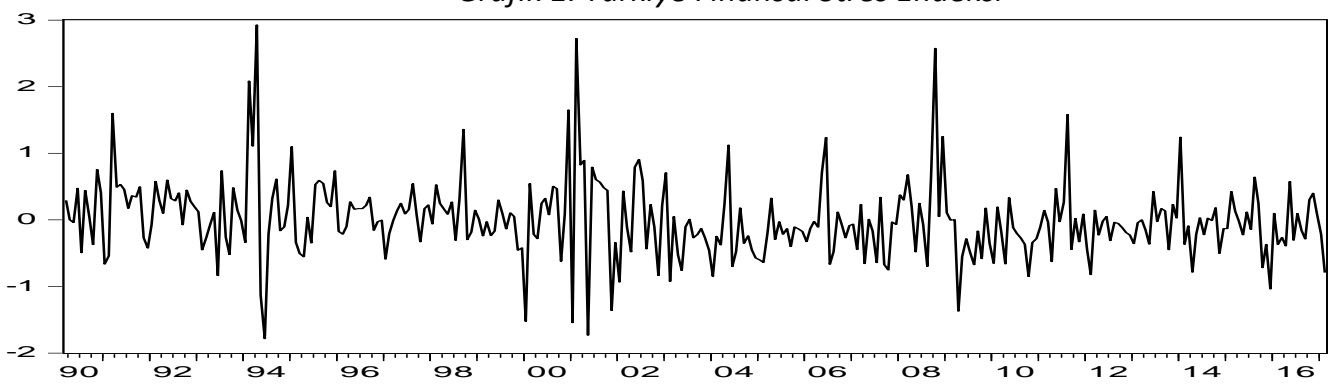

Endeksin zaman grafiğinde finansal stresin zirve yaptığı dönemlerin 1991, 1994, 1998, 2000 2001 ve 2008 kriz yılları olduğu görülmektedir. Finansal piyasalar 1991 Körfez savaşı, 1994 yılında Avrupa Para Sistem Kriz (ERM) ve Körfez Krizi, 1998 yılında ise Rusya Krizi olmak üzere dışsal şoklardan etkilenmiştir. 2002 yılında yaşanan politik gelişmeler ve erken genel seçim piyasalarda stresin artmasına neden olmuştur. Ayrıca 2011 yılında Euro bölgesinin yaşadığı borç krizi küresel büyümede azalmaya neden olurken, finansal piyasalarda stresin artmasına da yol açmıştır. 2013 yılına gelindiğinde ise küresel para politikalarındaki belirsizlik, yaşanan politik istikrarsızlıklar stresi arttıran unsurlar olurken, 2015 yılında küresel piyasalardaki belirsizliğin yaratmış olduğu oynaklıklar ve aynı yıl iki genel seçimin yapılması sonucu yaşanan politik istikrasızlıklar da stresi arttırmıştır. Finansal piyasalarda özellikle 2001 krizinden önce stresin daha yüksek olduğu görülmektedir. 2001 yılı sonrasında stresin daha az olma nedeni ise, 15 Mayıs 2001 yılında Güçlü Ekonomiye Geçiş Programı ile bankacılık sektörü için yapılan yapısal reformlara ağılık verilmiş olmasıdır. Bu sayede dış finansmana ağırlık verilerek finansal piyasaların kırılganlığının azalması sağlanmıştır. 
Yukarıda finansal stres endeksi oluşturulmuş ve zaman grafiğinde stresin yükseldiği dönemleri yakalamakta başarılı olduğu görülmüştür. Aşağıda ise yüksek stres dönemlerini belirlemek amacı ile yararlanılacak olan Markov rejim değişim modellerinden kısaca bahsedilmektedir.

\section{Yöntem}

Hamilton (1989) modeli olarak da adlandırılan Markov rejim modelinde, ekonomide yaşanan durgunluk ve genişleme dönemleri arasındaki rejim geçişleri, olasılık olarak ifade edilmektedir. Rejim geçişi ya da rejim kayması özelliği doğru şekilde uygulandığı zaman ekonomik dalgalanmalar çerçevesinde gerçekleşen patlama, durgunluk ya da daha karmaşık asimetri durumları modellenebilmektedir (Wang, 2008: 113).

Markov geçiş modelinde rejim, $t$ zamanında gözlemlenemeyen $s_{t}$ değişkeni tarafından belirlenmekte ve sürecin stokastik doğası gereği sistemin hangi rejimde olduğu kesin olarak bilinmemektedir. Ayrıca rejim geçişleri dışsal bir faktörün etkisindedir (Enders, 2014: 447).

Bunu basit bir örnek ile göstermek amacı ile sadece iki rejimin olduğu ve her iki rejimin de AR (1) sürecine sahip olduğu varsayımı ile;

$$
Y_{t}= \begin{cases}\emptyset_{0,1}+\emptyset_{1,1} Y_{t-1}+\varepsilon_{1 t} & s_{t}=1 \text { iken } \\ \emptyset_{0,2}+\emptyset_{1,2} Y_{t-1}+\varepsilon_{2 t} & s_{t}=2 \text { iken }\end{cases}
$$

modeli yazılabilir. Genel gösterim ise;

$$
Y_{t}=\emptyset_{0, s_{t}}+\emptyset_{1, s_{t}} Y_{t-1}+\varepsilon_{t}
$$

şeklinde yapılabilir (Enders, 2014: 447). Burada $\varepsilon_{1 t}$ ve $\varepsilon_{2 t}$ hata terimleri sıfır ortalamalı ve sabit varyanslı rastsal değişken dizisi olup birbirinden bağımsızdır, $\varepsilon_{i t} \sim$ i.i.d (Tsay, 2002: 135). Otoregresif katsayılar rejim 1'de $\phi_{1,1}$ iken rejim 2'de $\phi_{1,2}$ 'dir. Gözlemlenen veriyi yansıtan olasılık kuralını açıklamak için $s_{t}=1$ 'den $s_{t}=2$ 'ye geçişin nedenini ortaya koyan bir olasılık modeline ihtiyaç vardır. Markov zinciri, Markov rejim değişim modellerinin temelini oluşturmakta ve rejim değişim modellerinde sistemin hangi rejimde olduğunu belirleyen ve gözlenemeyen $s_{t}$ durum değişkeninin davranışlarını modellemek için kullanılmaktadır (Bildirici vd., 2010: 57).

Markov rejim değişim modellerinde rejim değişimleri, bir Markov zinciri sürecine göre tamamen stokastik bir şekilde ortaya çıkar (Granger, 1988: 13). $s_{t}^{\prime}$ nin $j$ gibi bir değere eşit olma olasılığı, sadece geçmiş en yakın değer olan $s_{t-1}$ 'e bağlı olduğu varsayımı altında $s_{t}$ 'nin izlediği birinci dereceden Markov zinciri;

$$
\mathrm{P}\left(s_{t}=j \mid s_{t-1}=i, s_{t-2}=k, \ldots Y_{t-1}, Y_{t-2}, \ldots\right) \mathrm{P}\left(s_{t}=j \mid s_{t-1}=i\right)=p_{i j}
$$

olarak gösterilir (Wang, 2008: 113). $p_{i j}$, rejimin $i$ durumunda iken $j$ durumuna geçme olasılığıdır. $s_{t}$ 'nin doğrudan gözlemlenemediği varsayıldığında, $s_{t}$ 'yi sadece $Y_{t}^{\prime}$ nin gözlemlenebilir davranışlarıyla açıklamak mümkündür. $Y_{t}$ ise iki kesim noktasını gösteren $\phi_{0,1}$ ve $\phi_{0,2}$ 'ye, otoregresif katsayıyı gösteren $\emptyset_{1,1}$ ve $\emptyset_{1,2}$ 'ye, iki durumlu geçiş olasılıklarını gösteren $p_{11}$ ve $p_{22}$ 'ye ve Gaussian şokların varyansı $\sigma^{2 \prime}$ ye bağlı olarak değişmektedir. Başka bir deyişle, $Y_{t}$ modelde yer alan parametrelere ve varyansa bağlı olarak değişmektedir (Hamilton, 2005: 2). 
Sürecin $N$ rejimli geçiş (transition) olasılıkları matrisi;

$$
P=\left[\begin{array}{ccccc}
p_{11} & p_{12} & \cdot & \cdot & p_{1 N} \\
p_{21} & p_{22} & \cdot & \cdot & p_{2 N} \\
\cdot & \cdot & \cdot & \cdot & \cdot \\
\cdot & \cdot & \cdot & \cdot & \cdot \\
p_{N 1} & p_{N 2} & \cdot & \cdot & p_{N N}
\end{array}\right]
$$

olarak gösterilebilir (Özdemir ve Akgül, 2015:358). Burada $p_{i j} ; t-1$ zamanında $i$ rejimden $t$ zamanındaki $j$ rejimine geçme olasılığını göstermekte olup her dönem değişkenin $N$ rejimden birinde olmak zorunda olduğu vurgulanmaktadır (Brooks, 2008: 465). Ayrıca geçiş olasılıkları negatif değer almaz ve her satırda yer alan olasılıkların toplamı bire eşittir.

İki rejimli bir Markov sürecinde rejimler $0-1$ veya $1-2$ olarak gösterilebilir. Burada gösterimler durumların $s_{t}=1$ ya da $s_{t}=2$ olmasına göre yapılacaktır. $s_{t}$ 'nin birinci dereceden Markov süreci izlediği durum için $p_{11}, p_{12}, p_{21}, p_{22}$ geçiş olasılık değerleri:

$$
\begin{array}{ll}
P\left(s_{t}=1 \mid s_{t-1}=1\right)=p_{11} & P\left(s_{t}=2 \mid s_{t-1}=1\right)=p_{12} \\
P\left(s_{t}=1 \mid s_{t-1}=2\right)=p_{21} & P\left(s_{t}=2 \mid s_{t-1}=2\right)=p_{22}
\end{array}
$$

olarak hesaplanmaktadır. Bu durumda geçiş matrisleri; ( $s_{t-1}=\mathrm{i}$ veri iken $s_{t}=\mathrm{j}$ olma olasılığı için)

$$
\boldsymbol{P}=\left[\begin{array}{ll}
p_{11} & p_{12} \\
p_{21} & p_{22}
\end{array}\right]=\left[\begin{array}{ll}
P\left(s_{t}=1 \mid s_{t-1}=1\right) & P\left(s_{t}=2 \mid s_{t-1}=1\right) \\
P\left(s_{t}=1 \mid s_{t-1}=2\right) & P\left(s_{t}=2 \mid s_{t-1}=2\right)
\end{array}\right]
$$

olarak gösterilebilir (Kuan, 2002: 4). $p_{11}$ sistemin rejim 1'de iken bir dönem sonra rejim 1'de kalma olasılığını gösterirken, $p_{12}$ rejim $1^{\prime}$ den rejim 2 'ye geçme olasılığını göstermektedir. Benzer şekilde, $p_{22}$ sistemin rejim 2 'de iken rejim 2 'de kalma olasılı̆ı̆ını gösterirken, $p_{21}$ rejim 2 'den rejim $1^{\prime}$ e geçiş olasılığını göstermektedir (Enders, 2014: 447). Daha genel bir ifade ile $p_{i j}, t-1$ zamanındaki $i$ rejiminden $t$ zamanındaki $j$ rejimine geçiş olasılığına eşittir. Ayrıca, $p_{i j}{ }^{\prime}$ lerin uygun olasılıkları için satır toplamlarının bire eşit olacak şekilde $p_{11}+p_{12}=1$ ve $p_{21}+p_{22}=1$ olması gerekmektedir (Franses ve Dijk, 2003: 82). $p_{i i}$ olasılık değerlerinin 1'e çok yakın olmaması yapısal parametrelerin sık değiştiğini gösterirken; 1'e yakın çıktığı durumlarda süreç daha kısa olarak ele alınacağından sadece birkaç rejim değişiminin meydana geleceği anlaşılmaktadır (Caporale ve Spagnolo, 2004: 236).

Hamilton (1989), MS modelinin tahmin edilmesi için iki basamaklı bir algoritma tanıtmıştır. Illk basamakta gözlemlenmemiş rejimlerin bileşik olasılık yoğunlukları da dâhil olmak üzere ana kütle parametreleri tahmin edilmekte, ikinci aşamada ise doğrusal olmayan filtreleme ve düzleştirmeler kullanılarak gözlemlenmemiş rejimler hakkında çıkarsamada bulunulmaktadır (Özdemir ve Akgül, 2015: 370). Başka bir ifade ile Hamilton modeli parametrelerinin tahmin süreci, log-olabilirlik fonksiyonunun maksimize edilmesi ile tahmin edilen parametrelerin kullanılarak gözlenmemiş rejim değişkeni $s_{t}$ için filtrelenmiş ve düzleştirilmiş olasılıkları bulmaya dayanır (Özdemir ve Akgül, 2015: 370). Filtrelenmiş olasılık, $t$ zamanında, sadece $t$ zamanına kadar olan bilgi kullanılarak, durum değişkeni $s_{t}$ 'nin hangi rejimde bulunduğu konusunda çıkarsamada bulunur. Düzleştirilmiş olasılık ise, $t$ zamanında rejimde bulunma çıkarsamasını yapabilmek için tüm örneklemi kullanır. İki olasılık arasındaki temel fark, $t$ zamanında rejime atanmak için kullanılan gözlem sayısıdır (Koç ve Akgül, 2013 :16). 


\section{Uygulama}

Uygulama aşamasında analizlere, serilerin durağan olup olmadığının belirlenmesi amacı ile birim kök testlerinin ardından bağımsız olup olmadığının başka bir ifade ile bu yaklaşımla doğrusal olup olmadığının belirlenmesi için BDS, Tsay ve Harvey vd. (2008) testlerinin yapılması ile başlamış, daha sonra da uygun MS modeli belirlenmiştir.

\subsection{Durağanlık ve Doğrusallık Testleri}

Doğrusal olmayan zaman serisi modellerinin tanımlanabilmesi için öncelikle serilerin doğrusal olmayan yapılarının ortaya konması gerekmektedir. Bu doğrultuda BDS bağımsızlık testi, Harvey vd. (2008) ve Tsay testleri yardımı ile endeksin doğrusal olmayan yapısı ortaya konulacaktır. Ancak serilerin ilk önce durağan olup olmadıklarının test edilmesi gerekmektedir. Bu nedenle endekse ADF ve PP birim kök testleri uygulanmış ve sonuçları Tablo 5'da verilmiştir.

Tablo 5: TFSE Birim Kök Sınaması

\begin{tabular}{cc}
\hline ADF Birim Kök Testi & PP Birim Kök Testi \\
\hline \hline$\tau$-istatistiği & $\tau$-istatistiği \\
$-17.27783^{* * *}$ & $-17.26465^{* * *}$ \\
\hline
\end{tabular}

Not: $* * * \% 1$ düzeyinde anlamlılığı ifade etmektedir.

Test istatistikleri, \%1 düzeyinde TFSE endeksinin durağan olduğunu göstermiştir. Durağan olduğu belirlenen endeks serisi için BDS testi yapılmış ve sonuçları Tablo 6 'da verilmiştir.

Tablo 6: TFSE Bağımsızlık/Doğrusallık Sınaması

\begin{tabular}{cccccccccc}
\hline Boyut & BDS ist. & St.Hata & Z-ist. & Olasılık & $\mathbf{C}(\mathbf{m}, \mathbf{n})$ & $\mathbf{c}(\mathbf{m}, \mathbf{n})$ & $\begin{array}{c}\mathbf{C}(\mathbf{1}, \mathbf{n}-(\mathbf{m}- \\
\mathbf{1}))\end{array}$ & $\begin{array}{c}\mathbf{c}(\mathbf{1}, \mathbf{n}-(\mathbf{m}-\mathbf{c}-\mathbf{C}(\mathbf{1}, \mathbf{n}-(\mathbf{m}- \\
\mathbf{1}))\end{array}$ & $\mathbf{1})^{\boldsymbol{n}} \mathbf{k}$ \\
\hline \hline $\mathbf{2}$ & 0.0186 & 0.0030 & 6.1553 & 0.0000 & 8891.0 & 0.1709 & 20296.0 & 0.3902 & 0.1523 \\
$\mathbf{3}$ & 0.0180 & 0.0026 & 6.7051 & 0.0000 & 3989.0 & 0.0771 & 20131.0 & 0.3895 & 0.0591 \\
$\mathbf{4}$ & 0.0131 & 0.0018 & 7.3194 & 0.0000 & 1850.0 & 0.0360 & 19965.0 & 0.3887 & 0.0228 \\
$\mathbf{5}$ & 0.0089 & 0.0010 & 8.5153 & 0.0000 & 913.0 & 0.0178 & 19856.0 & 0.3890 & 0.0089 \\
$\mathbf{6}$ & 0.0054 & 0.0005 & 9.5804 & 0.0000 & 453.0 & 0.0089 & 19725.0 & 0.3888 & 0.0034 \\
\hline
\end{tabular}

Tablo 6'da BDS testi $z$ istatistiği ve olasılık değerlerine göre, tüm boyutlarda \%5 anlamlılık düzeyinde serinin bağımsız olduğunu ileri süren sıfır hipotezinin reddedildiği görülmektedir. Böylece endeks serisinin tüm boyutlarda bağımlı, dolayısı ile doğrusal olmadığı ortaya konmuştur. Endeksin doğrusal olmayan yapısını ortaya koymak için ayrıca Harvey vd. (2008) ve Tsay testi uygulanmıştır. Tsay testi doğrusal model tahmin sonuçlarına Tablo 7 'de, doğrusal olmama test sonuçlarına ise Tablo 8'de yer verilmiştir. 
Eskişehir Osmangazi Üniversitesi ïBF Dergisi

Tablo 7: Tsay testi için Doğrusal Model Tahmin Sonuçları

\begin{tabular}{clllll}
\hline & Katsayı & T-İstatistiği & Varsayımlar & T-İstatistiği & Prob. \\
\hline \hline TFSE $_{\mathrm{t}-1}$ & 0.1135 & $2.17 * *$ & Otokorelasyon Testi: & & \\
D1991 & 1.6592 & $3.11^{* * *}$ & Ljung-Box Q- $\hat{\varepsilon}$ & 20.870 & 0.6464 \\
D1994 & 2.1229 & $3.99 * * *$ & Değişen Varyans Testi: & & \multirow{2}{*}{0.1185} \\
D2001 & 2.8982 & $5.39 * * *$ & Ljung-Box Q- $\hat{\varepsilon}^{2}$ & 32.320 & \\
\hline Not: $* * * \% 1$ ve ** \%5 düzeyinde anlamlılığı ifade etmektedir.
\end{tabular}

Not: *** \%1 ve ** \%5 düzeyinde anlamlılığı ifade etmektedir.

Doğrusal modelde yer verilen kukla değişkenler, kriz yılları için oluşturulmuş olan değişkenlerdir. Tablo 7'de yer verilen testler, modelin doğru tanımlanmış olduğunu ortaya koymaktadır.

Tablo 8: Harvey vd.(2008) ve Tsay Testi Sonuçları

\begin{tabular}{ccc}
\hline Harvey vd. (2008) Testi & Tsay Testi & \\
\hline \hline Test istatistiği & Test istatistiği & Prob. \\
10.02892 & 7.20864 & $9.94310 \mathrm{e}-007$ \\
\hline
\end{tabular}

Not: Harvey vd. (2008) testi kritik değerleri \%1, \%5 ve \%10 için sırasıyla 9.21, 5.99 ve 4.60'dır.

Tablo 8'da Harvey vd. (2008) test istatistiği ve bir gecikmeli doğrusal model için elde edilen Tsay test istatistiği değerlerinin kritik değerlerden büyük olması nedeni ile Ho hipotezinin red edildiği, başka bir ifade ile doğrusallığın reddedildiği görülmektedir. Bu da endeksin doğrusal olmayan zaman serisi modelleriyle incelenmesinin uygun olduğunu göstermektedir.

\subsection{Finansal Stres Endeksi için Markov Rejim Değişim Modeli}

Zaman serisi verisinin doğrusal bir yapısının olmadığı durumlarda, doğrusal olmayan modellerin kullanılması gerekmektedir. Bu çalışmada doğrusal olmadığı belirlenen finansal endeks yardımı ile kriz olasılıklarının hesaplanması için Markov rejim değişim modelinden yararlanılmıştır. İki rejimli modellerde $s_{t}=1$ normal stres dönemi (kriz olmayan dönem), $s_{t}=2$ yüksek stres dönemi (kriz dönemi) olarak tanımlanmıştır. Üç rejimli modellerde ise $s_{t}=1$ ve $s_{t}=2$ normal ve düşük stres dönemini, $s_{t}=3$ yüksek stres dönemini (kriz dönemi) tanımlamaktadır. Yüksek ortalama ve yüksek oynaklığa sahip rejim, yüksek stres dönemi olarak kabul edilirken, ortalaması ve oynaklığı düşük olan rejim iki veya üç rejimli olmasına göre düşük stres ya da normal stres dönemi olarak kabul edilmiştir.

Markov rejim değişim modellerinde rejim sayısına AIC, SC bilgi kriterleri için en küçük ve logolabilirlik oranı için ise en yüksek değerine göre karar verilmiş ve 3 rejimli model tercihi yapılmıştır. Aşağıda bu kriterlere göre rejim sayısına karar verilmiş endeks için en uygun Markov rejim değişim modeli yer almaktadır.

TFSE için sabitin (I) ve varyansın $(H)$ değişimlerine izin veren çeşitli MS modelleri denenmiş (Krolzig, 1997: 14) ve en uygun olduğuna karar verilen Markov rejim değişim modeli, MSIH(3) olarak belirlenmiştir. Sabit terimin değiştiği tanımlama, bir rejimden diğer rejime geçişin yumuşak olduğu durumlarda söz konusu olmaktadır (Koç ve Akgül, 2013:16).

Bu modelin tahmin edilmesi ile elde edilen bilgiler Tablo 9 'da verilirken aynı tabloda çalışmanın amacına uygun olarak sadece yüksek stres rejim dönemlerine yer verilmiştir. 
Tablo 9: TFSE Markov Rejim Değişim Modeli Tahmin Sonuçları: MSIH(3)-DR

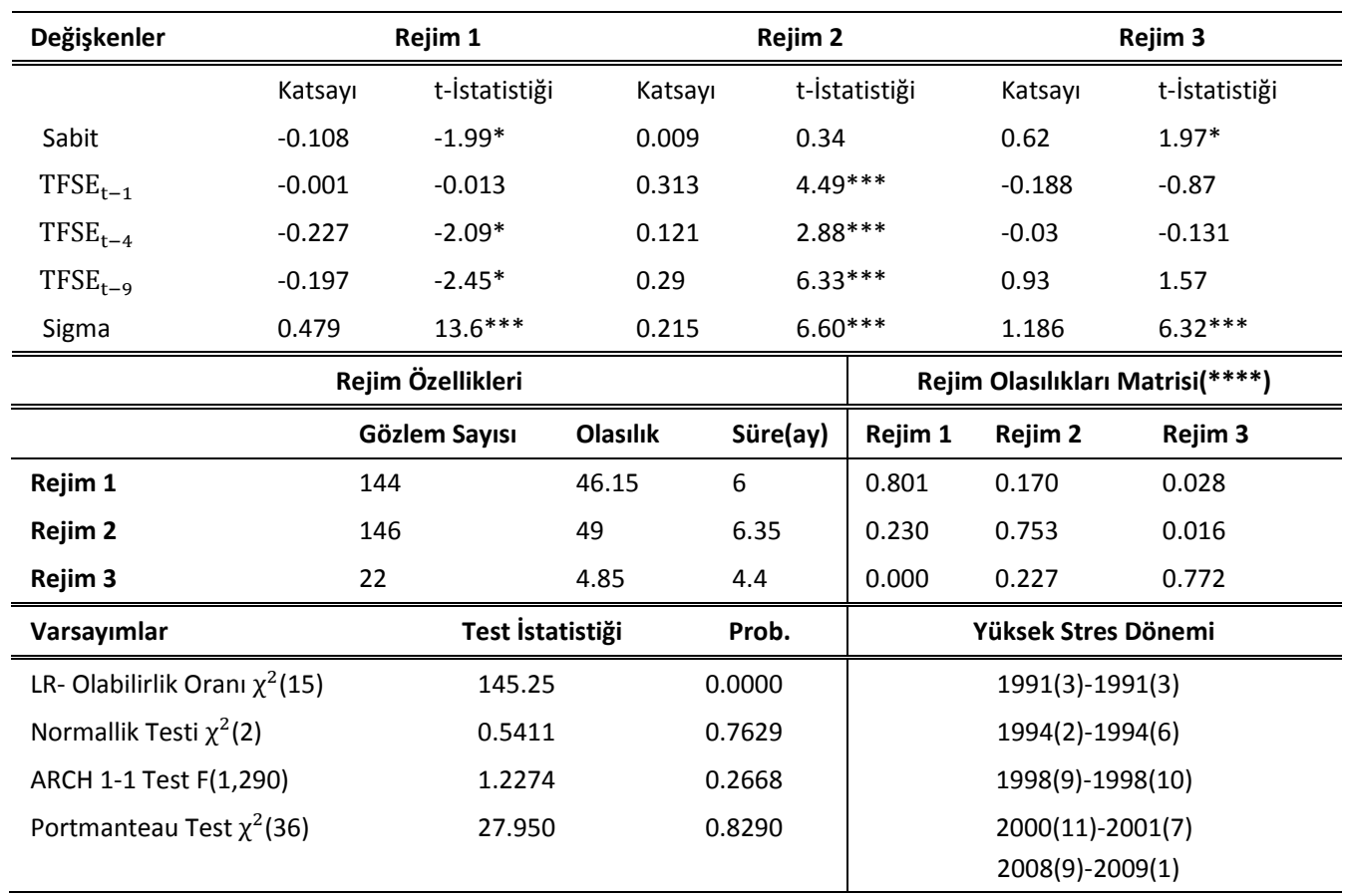

Not 1: ${ }^{* * *}, * *$ ve $*$ sırasıyla $\% 1, \% 5$ ve $\% 10$ anlamlılık düzeyini göstermektedir.

Not 2: **** Modelde rejim olasılıkları, satırlar toplamı bir olacak şekilde yazılmıştır.

TFSE için en uygun olduğu belirlenen MSIH(3)-DR modeli artıklarının varsayımları sağlayıp sağlamadığını görmek için hesaplanan LR, normallik, ARCH ve Portmanto testlerinin sonuçları, temel varsayımların sağlandığını göstermektedir. Tablo 9' da yer alan LR olabilirlik oranına göre serinin doğrusal olduğunu ileri süren sıfır hipotezi \%1 anlamlılık düzeyinde reddedilmiştir.

Rejim ortalaması ve varyansına göre rejim 1 normal stres dönemi, rejim 2 düşük stres dönemi, rejim 3 yüksek stres dönemi olarak adlandırılmıştır. Rejim geçiş olasılıklarına bakıldığında, rejim 1'de iken bir sonraki dönemde 1. rejimde kalma olasılığının 0,80; rejim 2'de iken 2. rejimde kalma olasılığının 0,75 ve rejim 3 'de iken 3 . rejimde kalma olasılığının 0,77 olduğu görülmektedir. Yine rejim geçiş olasılıklarına bakıldığında, rejim 1'de iken bir sonraki dönemde 2. rejimde olma olasılığının 0,17; rejim 2'de iken bir sonraki dönemde 1 . rejimde olma olasılığının 0,23 ve rejim 3'de iken bir sonraki dönemde 2. rejimde olma olasılığının 0,22 olduğu görülmektedir. Bu da her üç rejim için bir dönem sonra aynı rejimde kalma olasılıklarının yüksek olduğunu, yani rejimlerin kararlııı̆ını vurgularken rejimler arası geçiş olasılıklarının nispeten düşük olduğunu göstermektedir. Ayrıca toplam 312 gözlemin 144 gözlemi rejim 1'de, 146 gözlem rejim 2'de ve 22 gözlem de rejim 3'de yer almaktadır. Rejimlerde ortalama kalma süreleri ise 1. rejimde 6 ay, 2. rejimde 6 ay ve 3 . rejimde 4 aydır. Bu da yüksek stres döneminin 4 ay gibi bir sürede sonlanacağını göstermektedir.

MSIH(3)-DR modeline ait hem filtrelenmiş hem de düzleştirilmiş olasılıklar hesaplanmış ancak Grafik 2'de sadece MSIH(3)-DR modeline ait filtrelenmiş kriz olasılıklarına ait grafikler verilmiştir. Bu grafikler yardımı ile her rejimin kriz dönemleri belirlenmiş, rejim sınıflandırması yapılmıştır. 
Grafik 2: TFSE Filtrelenmiş Kriz Olasılıkları

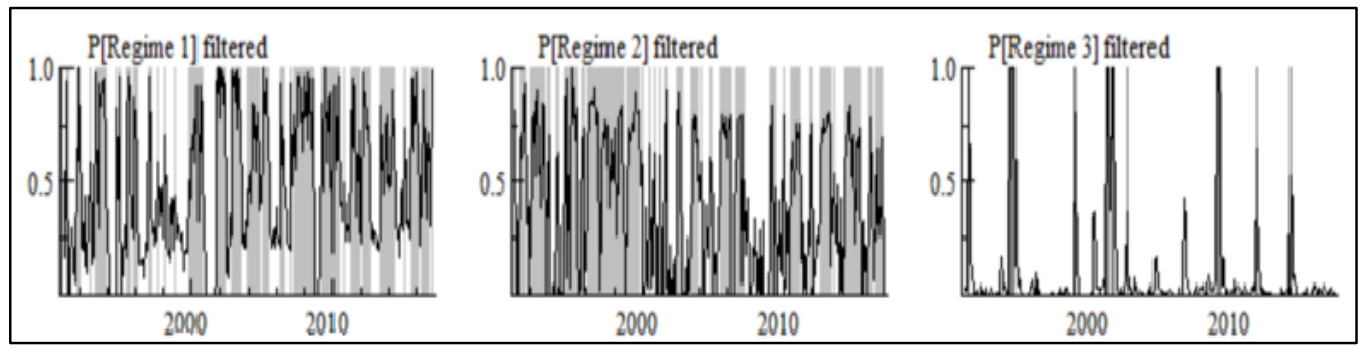

Rejim olasılıkları (Tablo 9), rejim 1 için 46.15; rejim 2 için 49 ve rejim 3 için 4.85 olarak hesaplanmıştır. Rejim olasılık matrisi ve Grafik 2' de yer verilen grafiklerde, ilk iki rejimin ani ve sık rejim değiştirme koşullarına sahip olmadığını, yüksek bir kalıcılık gösterdiğini vurgulamaktadır. Ayrıca Grafik 2'de yüksek stres rejimini gösteren rejim 3'ün rejim sınıflandırmasında ortaya çıkan 1991(3)-1991(3) ,1994(2)-1994(6), 1998(9)-1998(10), 2000(11)-2001(7), 2008(9)-2008(1) dönemleri açıkça görülmektedir. Bu dönemlerin Türkiye'nin yaşadığı tüm ekonomik kriz dönemlerine karşılık geldiği ve finansal stresin en yüksek olduğu dönemler olduğu ifade edilebilir.

Kriz dönemi olarak kabul ettiğimiz yüksek stres döneminde, 1991 yılının üçüncü ayından itibaren krizin ortaya çıktığı görülmektedir. 1994 krizi 2 ay, 2008 krizi bir ay öncesinden öngörülmüştür. Bu da endeksin, krizleri 1-2 ay öncesinden öngördüğü şeklinde yorumlanabilir. Ayrıca yüksek stres dönemleri 1998 ve 2000-2001 krizlerini de kapsamaktadır.

\section{Sonuç}

Finansal sektörü temsil edeceği düşünülerek seçilen değişkenlerden yararlanarak hesaplanan finansal stres endeksi TFSE'nin, Türkiye de 1990 sonrası ortaya çıkan tüm krizleri yakalamış olması, başka bir ifade ile yüksek stresin zirve yaptığı 1991, 1994, 1998, 2000-2001 ve 2008 kriz dönemlerini yakalamadaki başarısı nedeni sektörel olarak uygun bir endeks olduğu söylenebilir. Bu bağlamda yapılan analizler de, TFSE'nin finansal sistemik stresi ölçmede başarılı bir performans sergilediğini ortaya koymaktadır.

Bu endeks için tanımlanan Markov rejim değişim modelinin tahmin sonuçlarının yüksek stres dönemlerini kriz yılları olarak belirlemiş olması da oluşturulan endeksin Türkiye krizlerini öngörmede başarısını göstermektedir. Elde edilen bulgular, döviz, hisse senedi, tahvil piyasaları ile uluslararası rezervlerin, finansal sektördeki stresin önemli bir bölümünü açıkladığını ortaya koymuştur. Ayrıca Türkiye'de 1990 sonrası yaşanan yüksek finansal stres dönemlerinin ortak özelliklerinin döviz rezervlerinin yetersiz olması, yüksek sermaye giriş çıkışlarının döviz kurunda yarattığı oynaklık ve politik istikrarsızlıklar olduğu görülmektedir.

Sonuç olarak, yapılan analizlerin sonucunda, Türkiye için oluşturulan finansal stres endeksi çerçevesinde finansal piyasalar için döviz kuru oynaklığının, hisse senedi oynaklığının, ülke içi politika faiz oranı ile ABD politika faiz oranı arasındaki farkın ve uluslararası rezervlerin finansal piyasalardaki istikrarın izlenmesinde kullanılacak önemli değişkenler olduğu ifade edilebilir. 


\section{Kaynaklar}

Adanur Aklan, Nejla; Çınar, Mehmet; Kanalıcı Akay, Hülya (2015), “Financial Stress and Economic Activity Relationship In Turkey: Post-2002 Period", Journal of Management \& Economics, Vol.22, No.2: 567-580.

Balakrishnan, Ravi; Danninger, Stephan; Elekdağ, Selim; Tytell, Irina (2009), "The Transmission of Financial Stress From Advanced to Emerging Economies”, IMF Working Paper, WP/09/133, 1-52.

Bildirici, Melike; Alp Aykaç, Elçin; Ersin, Özgür Ömer; Bozoklu, Ümit (2010), iktisatta Kullanılan Doğrusal Olmayan Zaman Serisi Yöntemleri, 1.Baskı, İstanbul: Türkmen Kitabevi.

Brooks, Chris (2008), Introductory Econometrics for Finance, 2th Edition, Cambridge: Cambridge University Press.

Caporale, Guglielmo, Maria; Spagnolo, Nicola (2004), “Modelling East Asian Exchange Rates: a Markov-Switching Approach", Applied Financial Economics, Vol.14, No.4: 233-242.

Cardarelli, Roberto; Elekdag, Selim; Lall, Subir (2009), "Financial Stress, Downturns, and Recoveries”, IMF Working Paper, WP/09/100, 1-60.

Çevik, Emrah Ismail; Dibooglu, Sel; Kenc, Turalay (2013), "Measuring Financial Stress in Turkey", Journal of Policy Modeling, Vol.35, No.2: 370-383.

Çamlica, Ferhat; Gunes, Didem (2016), "Türkiye'de Finansal Stresin Ölçülmesi: Yöntemsel Bir Karşılaştırma”, Research and Monetary Policy Department, Central Bank of the Republic of Turkey, No.6.

Ekinci, Aykut (2013), "Financial Stress Index for Turkey”, Doğuş Üniversitesi Dergisi, C.14, S.2: 213-229.

Elekdağ, Selim; Kanlı, İbrahim Burak; Samancıoğlu, Zahid; Sarıkaya, Çağı (2010), "Finansal Stres ve İktisadi Faaliyet", Central Bank Review, C. 10, S.2:1-8.

Enders, Walter. (2014), Applied Econometric Time Series, 4th Edition. New York, John Wiley.

Franses, Philip, Hans; Van Dijk, Dick (2003), Non-Linear Time Series Models in Empirical Finance, 2th Edition, Cambridge: Cambridge University Press.

Granger, W.J. Clive (1998), "Overview of Nonlinear Time Series Specification in Economics" National Science Foundation Summer Symposia on Econometrics and Statistics, California.

Hakkio, Craig; Keeton, William (2009), "Financial Stress: What Is It, How Can It Be Measured, and Why Does It Matter", Economic Review-Federal Reserve Bank of Kansas City, Vol.94, No.2: 5-50.

Hamilton, James, Douglas (1989), "A New Approach to The Economic Analysis of Nonstationary Time Series and The Business Cycle", Econometrica: Journal of the Econometric Society, Vol.57, N.2: 357-384.

Hamilton, James, Douglas (2005), “Regime-Switching Models”, Unpublished Working Paper, University of California, San Diego, 1-15.

Hanschel, Elke; Monnin, Pierre (2005), "Measuring and Forecasting Stress in The Banking Sector: Evidence from Switzerland", BIS Papers, No.22: 431-449.

Harvey, I. David; Leybourne, J.Stephen; Xiao, Bin (2008), “A Powerful Test for Linearity When the Order of Integration is Unknown", Studies in Nonlinear Dynamics \& Econometrics, Vol.12, No.3: 1-22.

Hollo, Daniel; Kremer, Manfred; Lo Duca, Marco (2012), "CISS - A Composite Indicator of Systemic Stress in the Financial System", ECB Working Paper Series, No.1426: 1-49.

Illing, Mark; Liu, Ying (2003), "An Index of Financial Stress for Canada", Bank of Canada Working Papers, Bank of Canada, No.14: 1-52.

Illing, Mark; Liu, Ying (2006), "Measuring Financial Stress in a Developed Country: An Application to Canad", Journal of Financial Stability, Vol.2, No.3: 243-265.

Kaminsky, Graciela; Lizondo, Saul; Reinhart, Carmen (1998), "Leading Indicators of Currency Crises", IMF Staff Papers, Vol.45, N.1: 1-48.

Koç, Selçuk; Akgül, Işıl (2013), "Türkiye Ekonomisinin Rejim Yapısının MSVAR ile Belirlenmesi”, iktisat İşletme ve Finans, C.28, S.324: 9-34.

Krolzig, Hans-Martin (1997), Markov-Switching Vector Autoregressions: Modeling, Statistical Inference and Application to Business Cycle Analysis. Lecture Notes in Economics and Mathematical Systems, 454, 1th Edition, Berlin: Springer.

Kuan, Chung Ming (2002), "Lecture on The Markov Switching Model” Institute of Economics Academia Sinica, http://homepage.ntu.edu.tw/ ckuan/pdf/Lec-Markov_note.pdf, (Erişim: 02.10.2017). 


\section{Eskişehir Osmangazi Üniversitesi IïBF Dergisi}

Martinez Peria, Maria Soledad (1999), “A Regime-Switching Approach to Studying Speculative Attacks: A Focus on European Monetary System Crises", Development Research Group, World Bank.

Oet, Mikhail Victor; Eiben, Ryan; Bianco, Timothy; Gramlich, Dieter; Ong, Stephen (2011), "Financial Stress Index: Identification of Systemic Risk Conditions", Federal Reserve Bank of Cleveland, Working Paper 11-30, November.

Özdemir, Selin; Akgül, Işıl (2015), "Inflationary Effects of Oil Prices and Domestic Gasoline Prices: Markov-SwitchingVAR Analysis", Petroleum Science, Vol.12, N.2: 355-365.

Özdemir, Selin; Akgül, Işıl (2015), "Ham Petrol ve Benzin Fiyatlarının Sanayi Üretimine Etkisi: MS-VAR Modelleri ile Analizi”, Ege Akademik Bakış, C.15, S.3: 367-378.

Öztürkler, Harun; Türkmen, Göksel (2013), "Türkiye İçin Finansal Baskı Endeksi Oluşturulması”, Türkiye Ekonomi Politikaları Araştırma Vakfı Politika Notu, 201319, 1-8.

Sauer, Christine; Bohara, Alok (2001), “Exchange Rate Volatility and Exports: Regional Differences Between Developing and Industrialized Countries", Review of International Economics, Vol.9, N.1: 133-152.

Tsay, S. Ruey (2002), Analysis of Financial Time Series, Financial Econometrics, 2th Edition, University of Chicago: John Wiley and Sons, Inc.

Vermeulen, Robert; Hoeberichts, Marco; Vašíček, Borek; Žigraiová, Diana; Šmídková, Katerina; Haan, Jakop de (2015), "Financial Stress Indices and Financial Crises”, Open Economies Review, Vol.26, N.3: 383-406.

Wang, Peijie (2008), Financial Econometrics, 2th Edition, Routledge. 